\title{
Synthesis and Characterization of Schiff Bases Derived from 1-Naphthylamine Hydrochloride, Syria: Homs
}

\author{
Rawand Alsabra \\ Master student: Department of chemistry-Faculty of Science-Albaath University, Syria \\ Lena Radwan \\ Dr. for organometallic chemistry: Department of chemistry, Faculty of Science-Albaath University, Syria
}

\begin{abstract}
The three Schiff bases namely NPNA $\left(\mathrm{L}^{1}\right)$ : N-[(E)-Pheny lmethylene]Naphthalene-1-Amine, newly NNNA $\left(\mathrm{L}^{2}\right)$ : $\mathrm{N}-[(\mathrm{E})-1-N a p h t h y l m e t h y l e n e] N a p h t h a l e n e-1-A m i n e ~ a n d ~ N F N A\left(L^{3}\right)$ : N-[(E)-2-Furylmethylene] Naphthalene-1Amine have been synthesized in equimolar reaction of 1-Naphthylamine hydrochloride with or naphthalene-1carbaldehyde or 2-furfuraldehyde in the presence of acetic acid glacial. The characterization of Schiff bases was done by ${ }^{1} \mathrm{HNMR}, \mathrm{UV}-\mathrm{VIS}, \mathrm{IR}$, spectral studies and analytical data.
\end{abstract}

Keywords: Schiff bases, aromatic aldehyde, spectroscopic studies.

DOI: $10.7176 / \mathrm{CMR} / 13-3-02$

Publication date:October $31^{\text {st }} 2021$

\section{Introduction}

Schiff bases are named in the owner of Hugo Schiff (1834-1915) [1-2]. Their formula is $\{\mathrm{HR}-\mathrm{C}=\mathrm{N}-\mathrm{R}\} \mathrm{R}=$ aryl group and Hugo Schiff prove it in (1864) [1].They are formed by condensation of aldehyde compounds with primary amine compounds in alcoholic medium in the presence of acetic acid as catalyst to make PH ranges between(4.5-5) [3]. Schiff base is called imine, azomethine, aldimine and anil. Schiff base derived from aromatic aldehyde and aromatic amine is more stable because the having effective conjugation and readily synthesized. Schiff bases used as antibacterial [4]], antifungi [5], anti-inflammatory [6], analgesic [6] , anticancer [7] and corrosion Inhibition []]. In industry section they are used as antioxidant agents []ㅡ, and as primary compound to synthesis new compounds [10]. The goal of the study presented here is to synthesize from condensation of 1Naphthyl amine hydrochloride with benzaldehyde or naphthalene-1-carbaldehyde or 2-furfuraldehyde.

\section{Experimental}

\subsection{Materials and instrumentation}

1-Naphthyl amine hydrochloride was supplied from Titan Biotech LTD. Benzaldehyde was supplied from UniChem. naphthalene-1-carbaldehyde, acetonitrile, TLC aluminium sheets was supplied from Merck. 2-Furfural was supplied from Fluka. EtOH, $\mathrm{CHCl}_{3},\left(\mathrm{C}_{2} \mathrm{H}_{5}\right)_{2} \mathrm{O}, \mathrm{CH}_{3} \mathrm{COOC}_{2} \mathrm{H}_{5}, \mathrm{DMF}$, n-Hexan were supplied from SigmaAldrich. $\mathrm{CH}_{2} \mathrm{Cl}_{2}$ Were supplied from Surechem Products LTD. Acetic acid glacial, cyclohexan, were supplied from $\mathrm{BDH}$. IR measurements ( $\mathrm{KBr}$ pellets) were carried out on Jasco 4100 FT- Samples were dissolved in $\left(\mathrm{CD}_{3}\right)_{2} \mathrm{CO}$ with TMS as internal reference IR spectrometer. NMR measurements were performed on a Bruker $400 \mathrm{MHz}$ spectrometer.

Ultraviolet-Visible spectra were recorded using a Optizen UV 3220 Spectro- photometer in the range of 200-800 $\mathrm{nm}$ and DMF is used as a solvent. Elemental analyses (C, N,H) were analyzed on FEI Quanta 200 Scanning Electron Microscopes. Decomposing point of the compounds were recorded using Electro Thermal Melting Point Apparatus $\left(10-370{ }^{\circ} \mathrm{C}\right)$. Differential Thermal Analyzer (DTA) were recorded for only NFNA using Shimadzu.

\subsection{General procedure for the synthesis of the ligands NPNA, NNNA and NFNA}

solution of (3mmol, 0.03gr) of Benzaldehyde or (3mmol, 0.47gr) of naphthalene-1-carbaldehyde or (3mmol, $0.29 \mathrm{gr})$ of 2 -furfuraldehyde in $(6 \mathrm{ml})$ absolute ethanol added dropwise to a solution of $(3 \mathrm{mmol}, 0.55 \mathrm{gr})$ of 1 Naphthylamine hydrochloride in $(6 \mathrm{ml})$ absolute ethanol in round bottom flask $(50 \mathrm{ml})$, then $(1 \mathrm{ml})$ of acetic acid glacial was added to this solution. The mixture was refluxed $23 \mathrm{~h}$ for NPNA and $21 \mathrm{~h}$ for NNNA in an oil bath at $\left(77-79^{\circ} \mathrm{C}\right)$. The reaction was monitored through TLC. After completion of the reaction (TLC analysis) the flask was cooled on crush ice to afford a solid product. The precipitates obtained were filtered, washed with acetonitrile and ethanol. Then they recrystallization from $\left(\mathrm{CH}_{2} \mathrm{Cl}_{2}: \mathrm{EtOH}\right)$ in ratio $(1: 2)$. Then they driedunder vacuum.

Through TLC we mointred the reaction of Schiff bases by using mix of solvents: (cyclohexan: diethylether) in ratio (3:2) for NPNA, (cyclohexan: chloroform) in ratio (3:1) for NNNA, (n-hexan: Ethyl acetate) in ratio $(2: 1)$ for NFNA. The TLC is listed in Table 1.

I. N-[(E)-Phenylmethylene]Naphthalene-1-Amine NPNA (L' $\left.\mathbf{L}^{\mathbf{1}}\right)$ : Yield: 90.82(\%). Color (yellow). DP. 
$183^{\circ} \mathrm{C}$. IR $\left(\mathrm{KBr}, \mathrm{cm}^{-1}\right): 1636(\mathrm{HC}=\mathrm{N}) .{ }^{1} \mathrm{HNMR}\left(\mathrm{CD}_{3} \mathrm{COCD}_{3}, \delta, \mathrm{ppm}\right)$ 7.14-7.16 (2,d, $\left.\mathrm{Ar}\right), 7.3-7.4$ (3,d,Ar), 7.4-7.44 (2,t,Ar), 7.46-7.52 (4,tet,Ar) 7.92-7.98 (2,m, H-C=N, Ar). UV (DMF, nm) 301 $\left(\pi \rightarrow \pi^{*}, \mathrm{CH}=\mathrm{N}\right)$. Anal. Calc. For $\mathrm{C}_{17} \mathrm{H}_{13} \mathrm{~N}$ (231.29): C: 88.28; H: 5.67; N: 6.06; found: C: 88.18; H: $5.87 ; \mathrm{N}: 5.95$.

II. N-[(E)-1-Naphthylmethylene]Naphthalene-1-Amine NNNA (L $\left.{ }^{2}\right)$ : Yield: 84.76(\%). Color (yellow). DP. $310^{\circ} \mathrm{C}$. IR $\left(\mathrm{KBr}, \mathrm{cm}^{-1}\right): 1633(\mathrm{HC}=\mathrm{N}) .{ }^{1} \mathrm{HNMR}\left(\mathrm{CD}_{3} \mathrm{COCD}_{3}, \delta, \mathrm{ppm}\right)$ 7.02-7.03 (2,t,Ar), 7.24-7.33 (2,tet,Ar), 7.48-7.54 (2,t,Ar), 7.59-7.64 (2,t,Ar) 7.79-7.81 (2,d,Ar), 7.92-7.94 (2,d,Ar), 8.01-8.05 $(1, \mathrm{~d}, \mathrm{Ar}), 8.12-8.14(2, \mathrm{~m}, \mathrm{H}-\mathrm{C}=\mathrm{N}, \mathrm{Ar})$. UV (DMF, nm) $308\left(\pi \rightarrow \pi^{*}, \mathrm{CH}=\mathrm{N}\right)$. Anal. Calc. For $\mathrm{C}_{21} \mathrm{H}_{15} \mathrm{~N}$ (281.35): C: 89.65; H: 5.37; N: 4.98; found: C: 89.61; H: 5.58; N: 4.81 .

III. N-[(E)-2-Furylmethylene]Naphthalene-1-Amine NFNA $\left(\mathrm{L}^{3}\right)$ : Yield: 79.59(\%). Color (red). DP. $118^{\circ} \mathrm{C}$. IR $\left(\mathrm{KBr}, \mathrm{cm}^{-1}\right): 1637(\mathrm{HC}=\mathrm{N}) .{ }^{1} \mathrm{HNMR}\left(\mathrm{CD}_{3} \mathrm{COCD}_{3}, \delta, \mathrm{ppm}\right)$ 7.4-7.42 (2,m,Ar), 7.5-7.52 (5,m, Ar), 7.84-7.92 (4,m, H-C=N, Ar). UV (DMF, nm) $330\left(\pi \rightarrow \pi^{*}, \mathrm{CH}=\mathrm{N}\right)$. Anal. Calc. For $\mathrm{C}_{21} \mathrm{H}_{15} \mathrm{~N}(281.35)$ : C: 81.43 ; H: 5.01; N: 6.33; O: 7.23; found: C: 81.40; H: 5.04; N: 6.18; O: 7.18.

\section{Results and discussion}

The Schiff base NPNA (scheme1) was prepared by condensation in ethanol of 1-Naphthyl amine hydrochloride and benzaldehyde. The same method was used for the preparation of the ligand NNNA and NFNA. (scheme1) The structure of Schiff bases thus formed was established by IR, ${ }^{1} \mathrm{HNMR}$, UV and CHN analysis. The synthesized Schiff bases were soluble in DMF, DMSO. The composition of the ligands was consistent with their NMR, IR, and CHN data. The results of the elemental analyses of the ligands, which are recorded in Table 1, are in good agreement with those required by the proposed formulae.

\subsection{IR spectra}

The characteristic bands of IR spectra of ligands $\mathrm{L}^{1}, \mathrm{~L}^{2}$ and $\mathrm{L}^{3}$ are reported in Table 2. Peak corresponding to $v(\mathrm{C}=\mathrm{O})$ stretching vibrations was absent in IR spectra of $\mathrm{L}^{1}$ and, instead, a new band assigned to azomethine $v(\mathrm{HC}=\mathrm{N})$ linkage appeared at $1636 \mathrm{~cm}^{-1}$ confirming the formation of Schiff base [ $\left.\underline{3}\right]$. Similarly, the peak at 1633 $\mathrm{cm}^{-1}$ in $\mathrm{L}^{2}$ corresponds to $v(\mathrm{HC}=\mathrm{N})$ linkage $[\underline{3}]$, and similarly, the peak at $1637 \mathrm{~cm}^{-1}$ in $\mathrm{L}^{3}$ corresponds to $v(\mathrm{HC}=\mathrm{N})$ linkage $[\underline{3}]$. A medium intensity band due to $v(\mathrm{C}-\mathrm{O}-\mathrm{C})$ stretching vibration of furan appeared at 1200 $\mathrm{cm}^{-1}$ in the ligands $\mathrm{L}^{3}[\underline{3}]$.

Table 1

\begin{tabular}{|c|c|c|c|c|c|c|c|c|}
\hline \multicolumn{9}{|c|}{ Physical measurements and analytical data of the ligands $\mathrm{L}^{1}, \mathrm{~L}^{2}, \mathrm{~L}^{3}$. } \\
\hline \multirow[t]{2}{*}{ No } & \multirow{2}{*}{$\begin{array}{c}\text { molecular } \\
\text { formula }\end{array}$} & \multirow[t]{2}{*}{ DP $\left({ }^{\circ} \mathrm{C}\right)$} & \multirow[t]{2}{*}{ TLC } & \multirow{2}{*}{$\begin{array}{l}\text { Yield } \\
(\%)\end{array}$} & \multicolumn{4}{|c|}{ Elemental analysis (\%) calculate (found) } \\
\hline & & & & & $\mathrm{C}$ & $\mathrm{N}$ & $\mathrm{H}$ & $\mathrm{O}$ \\
\hline $\mathbf{L}^{1}$ & $\begin{array}{c}\operatorname{NPNA}\left(\mathrm{L}^{1}\right) \\
{\left[\mathrm{C}_{17} \mathrm{H}_{13} \mathrm{~N}\right]}\end{array}$ & 183 & $0.91^{*}$ & 90.82 & $\begin{array}{c}88.28 \\
(88.18)\end{array}$ & $\begin{array}{c}6.06 \\
(5.95)\end{array}$ & $\begin{array}{c}5.67 \\
(5.87)\end{array}$ & --- \\
\hline $\mathbf{L}^{2}$ & $\begin{array}{c}\mathrm{NNNA}\left(\mathrm{L}^{2}\right) \\
{\left[\mathrm{C}_{21} \mathrm{H}_{15} \mathrm{~N}\right]}\end{array}$ & 310 & $0.83^{* *}$ & 84.76 & $\begin{array}{c}89.65 \\
(89.61)\end{array}$ & $\begin{array}{r}4.98 \\
(4.81)\end{array}$ & $\begin{array}{r}5.37 \\
(5.58)\end{array}$ & --- \\
\hline $\mathbf{L}^{3}$ & $\begin{array}{l}\operatorname{NFNA}\left(\mathrm{L}^{3}\right) \\
{\left[\mathrm{C}_{15} \mathrm{H}_{11} \mathrm{NO}\right]}\end{array}$ & 125 & $0.85^{* * *}$ & 82.34 & $\begin{array}{c}81.43 \\
(81.40)\end{array}$ & $\begin{array}{r}6.33 \\
(6.17)\end{array}$ & $\begin{array}{c}5.01 \\
(5.04)\end{array}$ & $\begin{array}{r}7.23 \\
(7.18)\end{array}$ \\
\hline
\end{tabular}

$*_{-}$(cyclohexan: diethylether) in ratio $(3: 2), *_{-}$(cyclohexan: chloroform) in ratio $(3: 1)$

***- (n-hexan: Ethyl acetate) in ratio $(2: 1)$,

Table 2

IR, UV-Vis data of the ligands $\mathrm{L}^{1}, \mathrm{~L}^{2}, \mathrm{~L}^{3}$.

\begin{tabular}{|llllll|}
\hline No & Color & $\operatorname{lR}\left(\mathrm{cm}^{-1}\right)$ & $\mathrm{UV}(\mathrm{nm})$ & & $\mathrm{n} \rightarrow \pi^{*}(\mathrm{CH}=\mathrm{N})$ \\
\hline $\mathbf{L}^{\mathbf{1}}$ & Yellow & 1636 & 281 & 301 & 400 \\
\hline $\mathbf{L}^{\mathbf{2}}$ & Yellow & 1633 & 277 & 308 & 403 \\
\hline $\mathbf{L}^{\mathbf{3}}$ & Red & 1637 & 287 & 330 & 395 \\
\hline
\end{tabular}




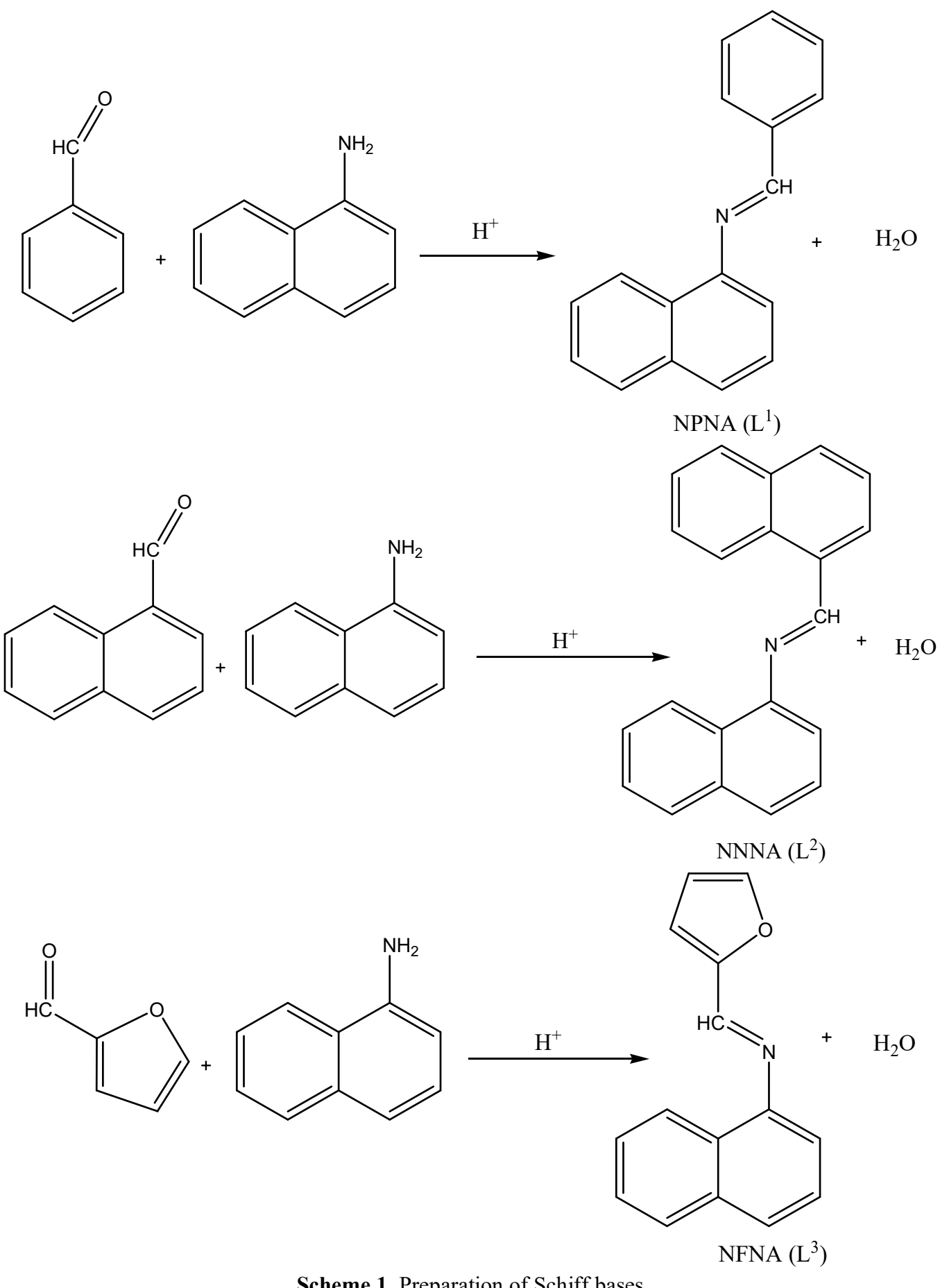

Scheme 1. Preparation of Schiff bases

\section{2. ${ }^{1}$ HNMR spectra}

The $1 \mathrm{H}$ NMR spectra have been recorded for ligand $\mathrm{L}^{1}, \mathrm{~L}^{2}$ and $\mathrm{L}^{3}$. The spectra of ligand $\mathrm{L}^{1}$ (Fig. 1) displayed azomethine $(\mathrm{H}-\mathrm{C}=\mathrm{N})$ proton as a multiply at 7.92-7.98 ppm [3] . In the spectra of the ligand $\mathrm{L}^{2}$ (Fig. 2) the azomethine $(\mathrm{H}-\mathrm{C}=\mathrm{N})$ proton appeared as doublet at 8.12-8.14 ppm [3]].

Similarly In the spectra of the ligand $\mathrm{L}^{3}$ (Fig. 3) the azomethine $(\mathrm{H}-\mathrm{C}=\mathrm{N})$ proton appeared as multiply at 7.84-7.92 ppm []ㅡ. 


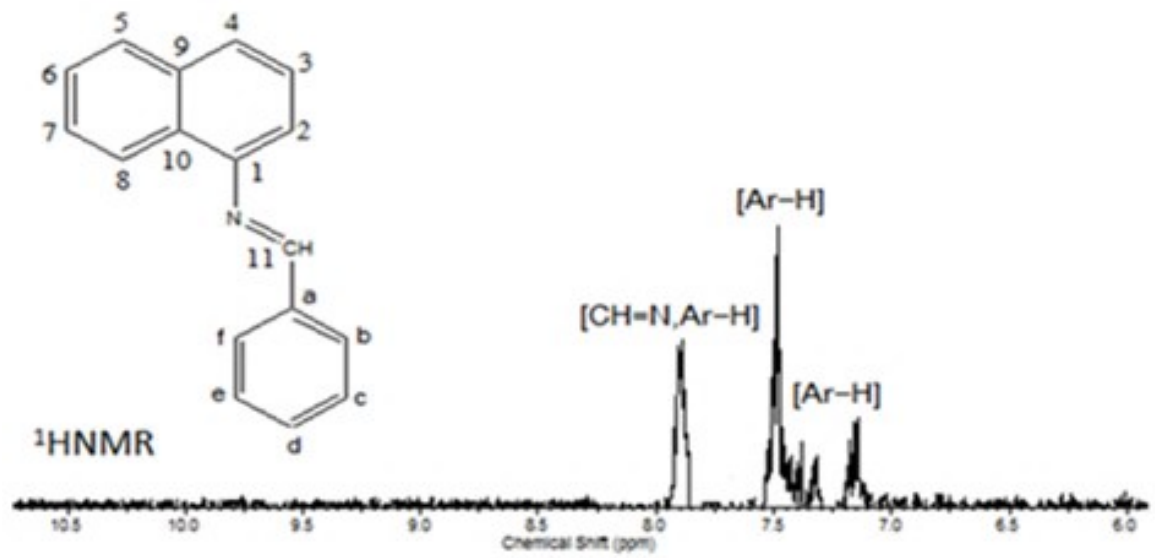

Fig.1. ${ }^{1} \mathrm{HNMR}$ spectrum of $\mathrm{L}^{1}$ ligand

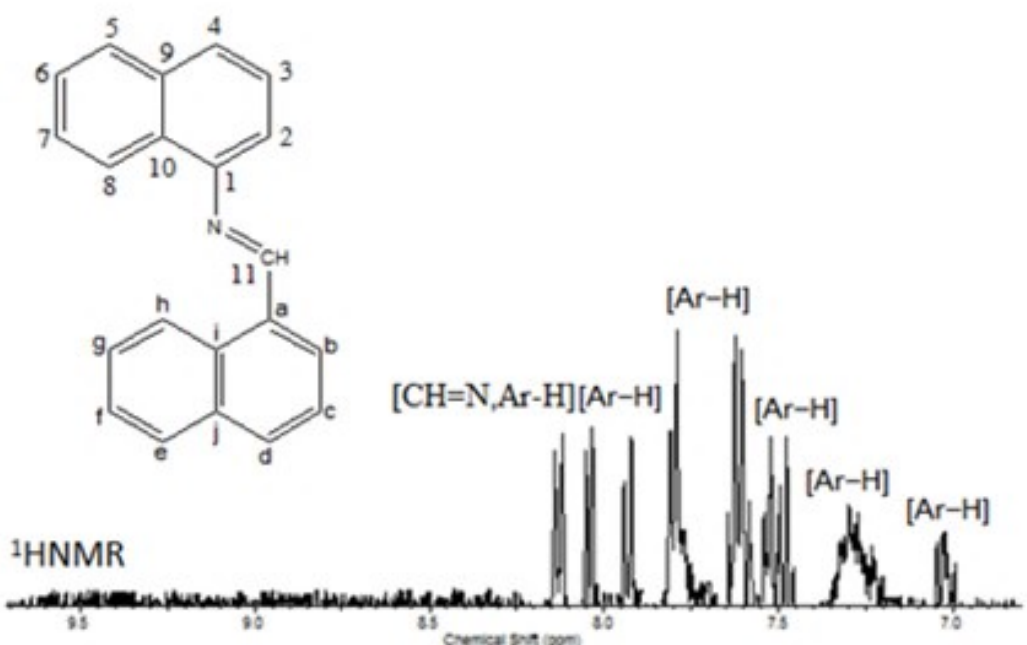

Fig.2. ${ }^{1} \mathrm{HNMR}$ spectrum of $\mathrm{L}^{2}$ ligand

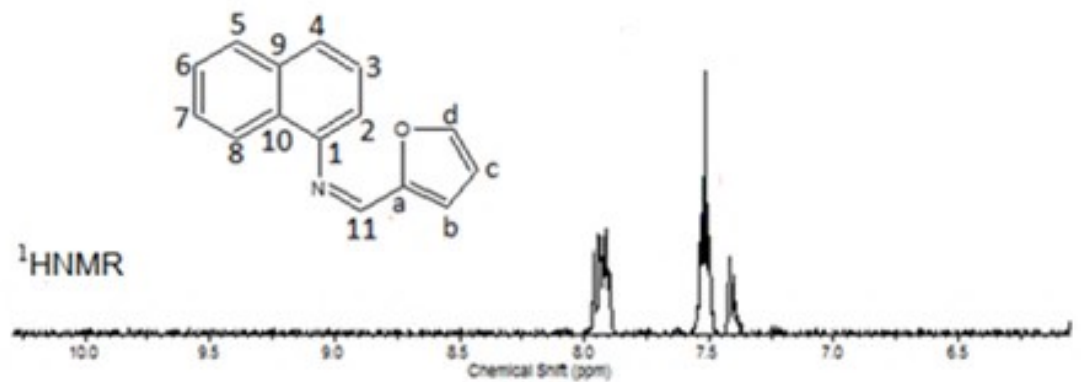

Fig.3. ${ }^{1} \mathrm{HNMR}$ spectrum of $\mathrm{L}^{3}$ ligand

\subsection{Electronic spectra}

The electronic spectra of the ligands and their complexes were recorded in DMF medium at room temperature. All the spectra of the ligands show band in range $(301,308,330 \mathrm{~nm})$ are attributable to the transition $\left(\pi \rightarrow \pi^{*}\right)$ of the azomethine corresponding of the ligands $\left(\mathrm{L}^{1}, \mathrm{~L}^{2}, \mathrm{~L}^{3}\right)$ respectively $[\underline{12}, \underline{11,5}]$. 


\subsection{Thermal analysis}

The DTA curve of the ligand $\mathrm{L}^{3}$ (Fig 4) shows an endothermic band at $84.87^{\circ} \mathrm{C}$ which represent the loss of lattice water [13].

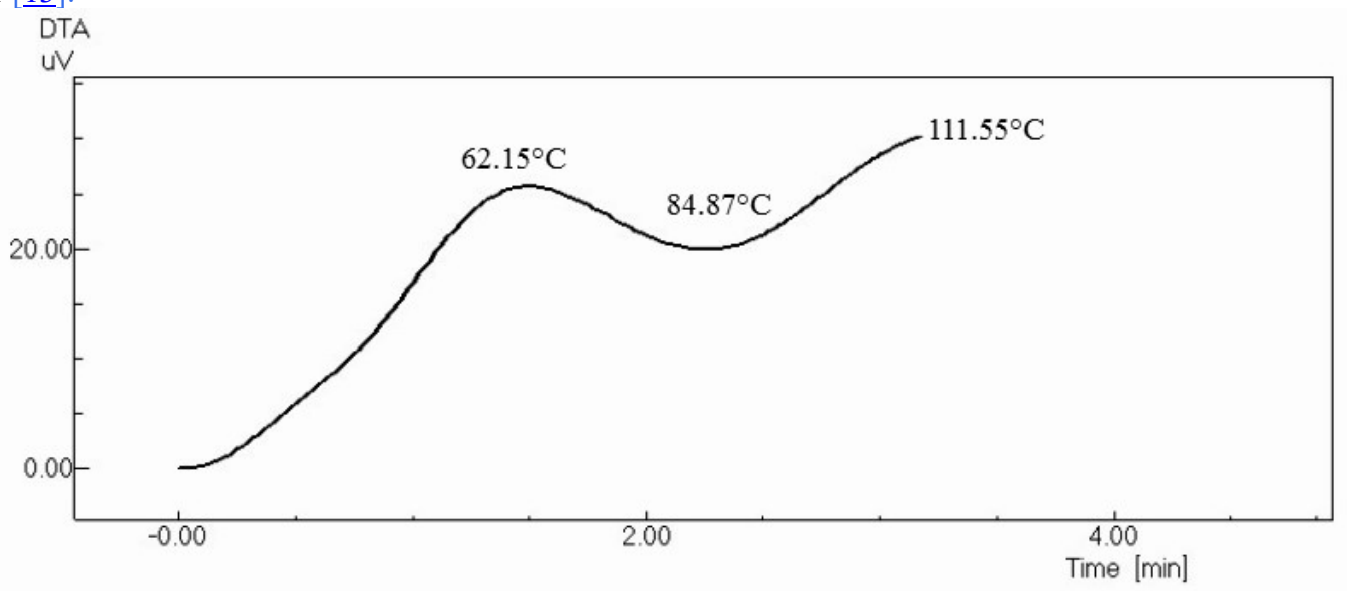

Fig.4. DTA curve of $\mathrm{L}^{3}$ ligand
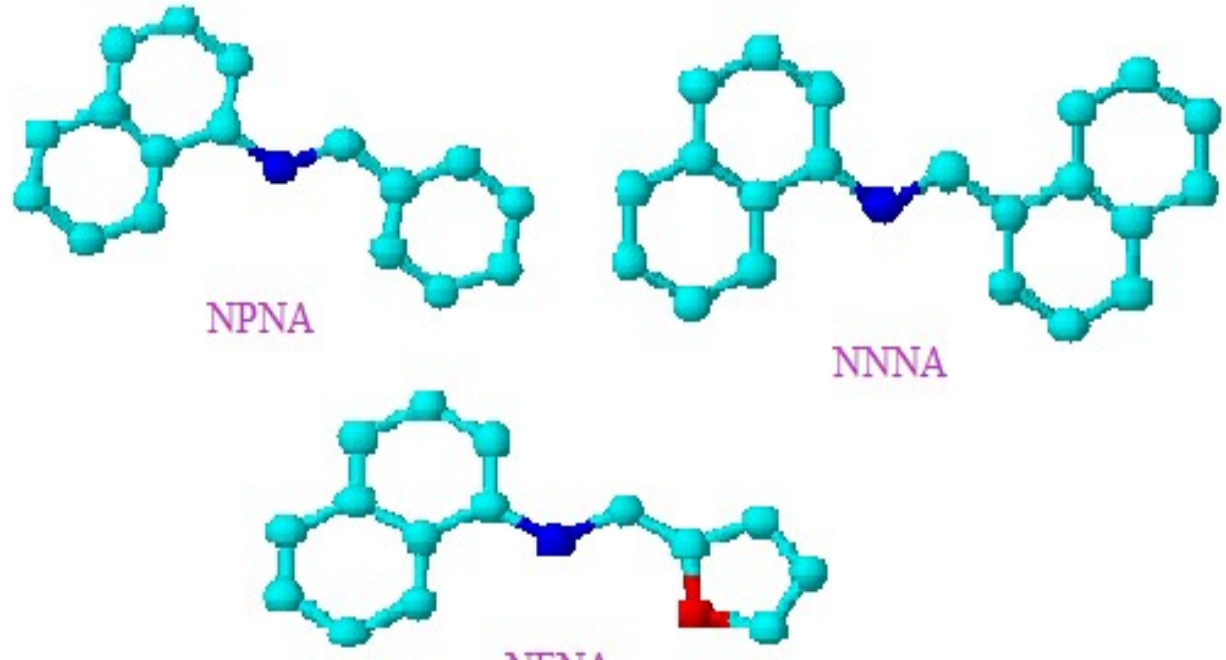

NFNA

NNNA

Scheme 1. structure of Schiff bases

\section{Conclusion}

Three Schiff bases mono dentate NPNA, NNNA and di dentate NFNA were synthesized from 1-Naphthyl amine hydrochloride with benzaldehyde or naphthalene-1-carbaldehyde or 2-furfuraldehyde. The ligands were confirmed from ${ }^{1} \mathrm{HNMR}, \mathrm{UV}-\mathrm{VIS}$, IR, spectral studies and analytical data.

\section{References}

[1]- H. Schiff. (1864), "Eine neue reihe organischer basen”, Justus Liebigs Annalen Der Chemie, 131, 118-119.

[2]- H. Schiff. (1884), "Ueberein condensations product aus salicylaldehyde", Berichte Der Deutschen Chemischen Gesellschaft, 17, 770-771.

[3]- N. D. Pandya. (2006), "Synthesis and physico chemical studies of some organic compounds", PhD Presentation of Saurashtra University.

[4]- M. N. Ibrahim, S .A. I. Sharif, A. N. El-tajory \& A. A .Elamari. (2011), "Synthesis and antibacterial activities of some Schiff bases", E-Journal of Chemistry, 8, 212-216.

[5]-Y. Prashanthi \& S. Raj. (2010), "Synthesis and characterization of transition metal complexes with N,O; N,N and S,N-donor Schiff base ligands", Journal of Scientific Research, 2, 114-126.

[6]- S. Sharma A, D. K. Jain, A. Aggarwal \& N. S. Gill. (2012), "Synthesis characterization and 
pharmacological evaluation of novel Schiff bases of imide moiety", J. Med. Sci, 12, 61-69.

[7]- M. Köse, G. Ceyhan, M. Tümer, I. Demirtas, I. Gönül \& V. McKee. (2015), "Monodentate Schiff base ligands: Their structural characterization, photoluminescence, anticancer, electrochemical and sensor properties", Spectrochimica Acta Part A:Molecular and Biomolecular Spectroscopy, 137, 477-485.

[8]- B. Sarikaya. M. Ceruso, F. Carta \& C. T. Supuran. (2014), "Inhibition of carbonic anhydrase isoforms I, II, IX and XII with novel Schiff bases: Identification of selective inhibitors for the tumor associated isoforms over the cytosolic ones", Bioorganic and Medicinal Chemistry, 22, 5883-5890.

[9]- N. A. Negm, M. F. Zaki \& M. A. I. Salem. (2009), "Synthesis andevaluation of 4-diethyl amino benzaldehyde Schiff Base cationic aphiphiles as corrosion inhibitors for carbon steel in different acidic media", J. Surfact. Deterg, 12, 321-329.

[10]- K. Hariprasath \& I. S. babu. (2014), "Synthesis and pharmacological screening of Schiff'S base metal complexes of sulphanilamide", Asian Journal of Pharmaceutical Analysis and Medicinal Chemistry, 2, 119126.

[11]- E. T. Shamkhy \& I. H. T. A.Karkhi. (2011), "Preparation of new Schiff base derived from cyclohexylamine with piperonaldehyde and its $\mathrm{Cu}^{+2}, \mathrm{Co}^{+2}$ and $\mathrm{Rh}^{+3}$ metal complexes"; Oriental Journal of Chemistry, 27, 1403-1408.

[12]- A. Bhalu, K. Vilapara, M. Maru \& M. Shah. (2014), "Synthesis and characterization of Cu(II), Ni(II) and Co(II) based Schiff base complexes", International Letters of Chemistry, Physics and Astronomy, 12, 5155.

[13]- S. A. A. Enein. (2008), "Polymeric and sandwich Schiff's bases complexes derived from 4,4'methylenedianiline Characterization and thermal investigation", Journal of Thermal Analysis and Calorimetry, 91, 929-936. 